\title{
ESRC-DFID Research for Policy and Practice:
}

\section{Quality teaching}

July 2018

\section{Foreword}

$\mathrm{T}$ eachers are crucial to achieving the ambitions articulated in Sustainable Development Goal 4, which aims to ensure that no one should be left behind in education. Their motivation, skills and knowledge will literally determine whether hundreds of millions of children are able to see a path out of the global learning crisis.

However, the process of teaching - and what truly makes it good quality - remains something of a 'black box' to both academics and practitioners. That should perhaps not be surprising: without the appropriate support, teaching in developing countries can be a solitary and often lonely profession for teachers who are struggling against so many odds. I am delighted therefore that this collection of ESRC-DFID funded research sheds light on that process.

From evidence across three continents, some of the key learnings that have emerged include: how more flexible, locally driven models of recruitment and support can be made available affordably and at scale in Honduras; and, drawing evidence from China, how Professional Learning Communities can be a strong factor for building peer collaboration and support among teachers, particularly if backed by the right school support structures and embodying some key principles. The research also highlights how enhanced classroom practice tools can significantly strengthen the granularity of feedback that teachers receive in Uganda; and how a combination of pre-service and in-service training in Ethiopia led to more learnercentred teaching, and with it learners' own engagement in the education process.

As a practitioner I am excited about starting to apply these lessons in our work at STIR Education, and I hope to contribute our experience back to the ESRC-DFID learning community. I hope other readers will feel very much the same and will delve into the valuable insights contained in this digest

\section{Sharath Jeevan}

Founder and CEO, STIR Education

www.stireducation.org

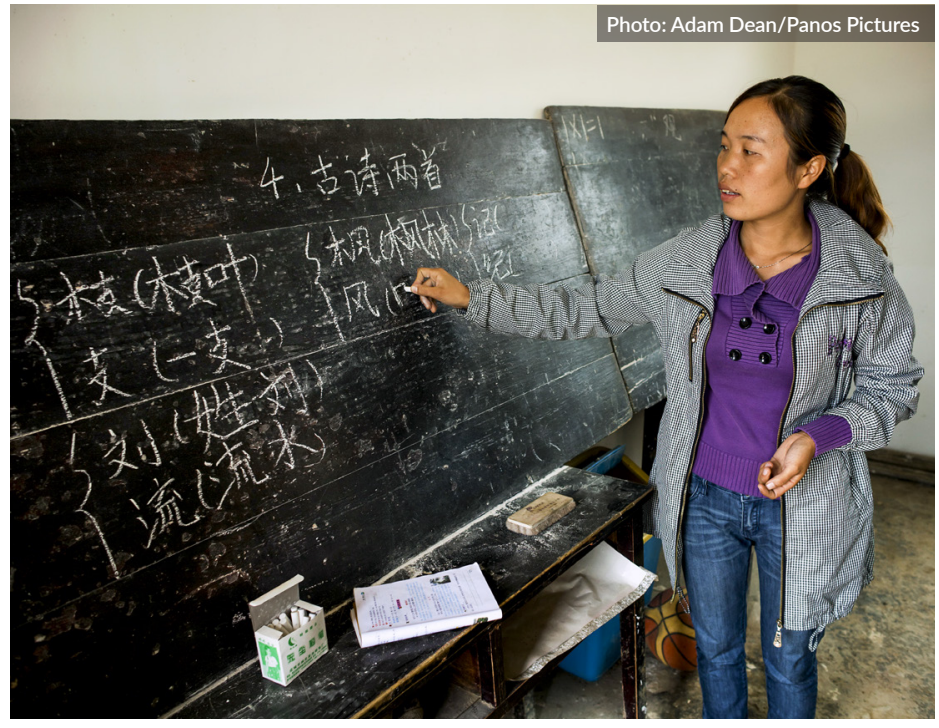

A teacher writes on a makeshift blackboard in China.

\section{Key messages}

- Provide new teachers with well-structured induction programmes to support them in the classroom.

- View teacher development as a continuum, providing teachers with opportunities, support and incentives to continue to improve.

- Use classroom observations to feed back to teachers to boost motivation and effort, leading to further improved teaching.

- Adopt pre-service and in-service training to achieve more learner-centred teaching, and to encourage learners' own engagement. 


\section{How innovative teacher training and recruitment approaches are improving learning outcomes in rural Honduras}

In Honduras, the average 11-year-old child leaves primary school with dramatically lower reading and mathematics levels than those of nine-year-old children in developed countries, and 30 per cent of students don't finish primary school without repeating grades. To combat poor performance in rural areas, the government has looked to the Sistema de Aprendizaje Tutorial or 'SAT' model for secondary schools - a partnership between government and local non-government organisations (NGOs). The model focuses on quality teacher training, flexible teacher contracts and unconventional recruitment methods.

Confronted with a growing number of under-prepared primary school graduates in rural areas, the Honduran government has prioritised the cost-effective expansion of SAT schools. These offer a formal, alternative secondary school education focused on the development of relevant knowledge and skills, and service-oriented values that rural youth need to become productive members and leaders of their communities.

Researchers from the University of California, Berkeley, and the Universidad Pedagógica Nacional Francisco Morazán, Honduras, have found that the SAT system is effective for improving teaching and learning outcomes in developing countries, particularly in rural contexts. Earlier research found that students in Honduran SAT schools had test scores that were 45 per cent higher than children who attended traditional schools in nearby villages. Building on that evidence, the researchers wanted to examine and understand the features of the SAT model to try to explain these learning gains.

During 2008, baseline data was collected from 1,426 graduating sixth graders from 94 rural SAT schools and traditional Centros de Educación Básicos (CEB) schools. Students completed background questionnaires and achievement tests in mathematics and language; household surveys were given to parents and/or guardians; and headteachers, teachers, parents and local education authority staff completed questionnaires. Teacher professional development sessions and classroom teaching practices were also observed.

The research identified a number of innovative features of the SAT system involving recruitment processes, professional development and the ongoing support of teachers, which address some of the major challenges in improving the quality of teaching in developing country contexts:

\section{- Teacher recruitment and retention}

To address the challenge of too few teachers, particularly in rural areas, the SAT model advertises positions in rural communities through radio announcements. Potential candidates are invited for screening by the local government, and those who meet the requirements can begin the training process. The recruitment of individuals who are from rural areas results in higher rates of teacher retention in the programme.

\section{- Teacher training}

New teachers participate in two-week in-service training courses that precede each trimester of the academic year - totalling 250 hours of professional development each year. Teachers receive ongoing monitoring and instructional support from a network of field supervisors. Teachers are trained with the same curriculum that they will impart to students, allowing them to master the content. They develop the attitude that they can learn alongside and from their students - allowing them to embrace student-centred learning.

\section{- Ongoing professional support and accountability}

SAT teachers are visited by an asesor (adviser, similar to a teaching 'coach') once every two weeks. The role of the coach is to 'accompany' teachers in their classroom - to observe their teaching and to offer support. The coach also administers student tests each trimester to keep track of student learning outcomes and step in if they find deficiencies. These features create a system of accountability that supports ongoing professional development.

This research identifies features of the SAT model that can inform the design and reform of education systems to improve teaching effectiveness. Furthermore, the case of the SAT school model demonstrates that high quality teaching and learning can happen, even at scale.

In Honduras, the project team closely engages with government officials, including the First Lady and Minister of Education, and with donors to examine how the SAT model can be expanded and used in other communities. Project team members have joined a number of high-level international policy discussions to share findings from the study of SAT schools to ensure that their evidence influences education reform in Latin America. For example, following the sharing of the project findings, UNICEF has included SAT principles in its global secondary education guidance note. According to UNICEF, SAT serves as a concrete example of a programme that has been scaled up successfully by national governments to expand access to secondary education.

Ingrid Sanchez-Tapia, an Education Specialist at UNICEF explained, 'A programme like SAT invites us to re-think how to achieve SDG4 - or 12 years of education for all - through pedagogical innovation to reach the most marginalised adolescents.'

Project title: Examining effective teaching in rural Honduran secondary schools.

\section{Erin Murphy-Graham}

Graduate School of Education

University of California, Berkeley, USA 


\section{Can a classroom observation tool improve teaching in Uganda?}

How teaching practices and classroom processes affect student learning outcomes is of global interest. Researchers from New York University have developed a reliable, valid and cost-effective observation tool that could be used in low-resource contexts and provide teachers with feedback for improving practice.

Research shows that effective teachers are the most important contributory factor in student achievement. Although curricula, reduced class size, district funding, family and community involvement all contribute to school improvement and student achievement, the most influential factor is the teacher. Yet it has become clear that the professional development needed to support teachers is often lacking and how effectively they function within classrooms is ineffective. In many parts of the globe, teachers who need the most professional development (such as new or underqualified teachers) often receive the least. Though there has been a long history in measuring pedagogical practices and processes, there is a recognised need for improved instruments and methodologies to gauge elements of classroom quality and effective teaching.

The 'Teacher Instructional Practices and Processes System' (TIPPS) observational tool examined the quality of teaching practices and classroom processes through live observations in Uganda. It was hoped that the results would provide helpful feedback to teachers for improved teacher performance. Areas of observation included students' ability to solve complex problems, and the teacher's ability to manage and promote a positive classroom environment.

The study, undertaken in collaboration with the Ugandan Ministry of Education and the World Bank, used TIPPS data collected in the classrooms of 197 Ugandan secondary schools and matched it with eighth grade achievement data from biology, English and mathematics. Pairs of locally recruited observers were trained to observe classrooms and were asked to match their observations to a manual that outlines 18 behavioural indicators known as 'TIPPS dimensions'. Dimensions could be added or deleted as appropriate to the context.

\section{Findings}

Out of the 18 dimensions created, 13 of them revealed sufficient variance and good to high levels of reliability across different assessors using the tool in the same context.

Based on the results in Uganda, TIPPS has shown itself to be a promising tool in terms of use and applicability in poorly resourced country contexts. Specifically:

- Three key dimensions of quality teaching emerged in Uganda: 'Instructional Strategies' which includes student-centred learning such as the encouragement of student questions and ideas; 'Sensitive and Connected Teaching' which refers to a teacher's ability to connect lessons to everyday life and sensitiveness

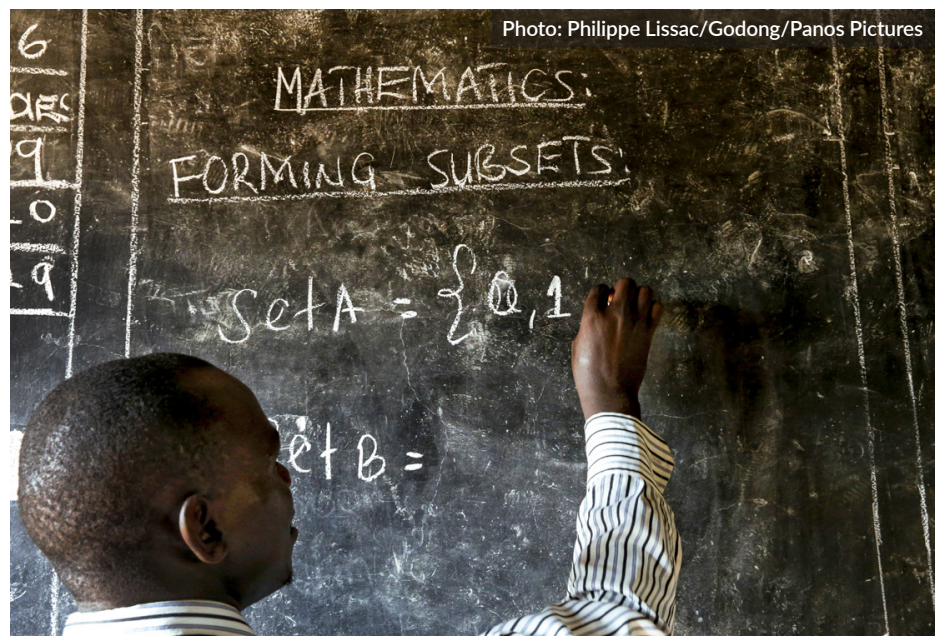

Uganda: A teacher writes maths formulas on a blackboard at a school.

to respond to students' needs; and, 'Deeper Learning' which characterises a teacher's ability to break down concepts to help facilitate student learning.

- The dimensions appear to have subject-specific relationships in secondary schools to academic subjects. For example, a teacher's ability to connect what students are learning to everyday life resulted in a trend towards better performance in biology.

- Individual items of the tool also have meaningful associations with learning outcomes. For example, in English, feedback was related directly to improved student performance in that subject.

The researchers found that the TIPPS observational tool was successful in measuring high quality education, with the potential to serve as a feedback tool in Ugandan secondary schools.

The findings were significant in that they provided important insights into the critical mechanisms at work in the classroom, as well as demonstrating that TIPPS has a role to play in teacher quality improvement in low-income country contexts.

Further refinements have been made based on the data obtained, including the development of the instrument for different ages. Based on these findings, TIPPS is now also being used to mentor teachers in India, where the Kaivalya Education Foundation is using TIPPS to help improve teaching practices. Additionally, an early childhood education and primary version of TIPPS is being used in Ghana.

Project title: Toward the Development of a Rigorous and Practical Classroom Observation Tool: The Uganda secondary school project.

\section{Professor Edward Seidman}

Professor, Applied Psychology

Psychology and Social Intervention Program and Global TIES for Children New York University, New York NY, USA

\section{SEE ALSO:}

Altet, M.; Paré-Kaboré, A. and Sall, H.N. (2016) OPERA, 'Observation des Pratiques Enseignantes dans leur rapport avec les apprentissages des élèves', http://opera.ifadem. org/sites/default/files/pdf/OPERA-rapport-final.pdf

López Bóo, F.; Araujo, M.C. and Tome, R. (2016) 'How is Child Care Quality Measured?', https://publications.iadb.org/bitstream/handle/11319/7432/How-is-child-care-qualitymeasured.pdf
Seidman, E.; Kim, S.; Raza, M.; Ishihara, M. and Halpin, P.F. (2018) 'Assessment of pedagogical practices and processes in low and middle income countries: Findings from secondary school classrooms in Uganda', Teaching and Teacher Education 71:283-296, doi: 10.1016/j.tate.2017.12.017

Wolf, S.; Raza, M.; Kim, S.; Aber, J.L.: Behrman, J. and Seidman, E. (forthcoming) 'Measuring and predicting classroom process quality in Ghanaian pre-primary classrooms using the Teacher Instructional Practices and Processes System (TIPPS)', Early Childhood Research Quarterly 


\section{Can Professional Learning Communities improve teaching quality in China?}

As the world's most populous country, China regards the development of a high quality teacher workforce as essential to the future prosperity of its people. However, a lack of opportunities to participate in professional development - particularly in impoverished areas - is a key drawback to raising the quality of compulsory education provision.

In 2010, a ten-year national plan for education reform and development in China issued by the Chinese Ministry of Education included the requirement to'...overhaul quality evaluation, and examinations, revamp teaching methods and approaches, and put a modern school system in place.' As a result, schools have been given greater autonomy and are encouraged to contribute to their own curriculum to support students' all-round development.

These reforms provide an opportunity for schools to become more effective 'Professional Learning Communities' (PLCs) where teachers learn from and with each other, and where they come to see themselves as a community of teachers who focus on implementing new ideas and practices to support the academic performance of students. While the approach varies in different contexts, PLC activities might include teachers meeting regularly to share expertise, workshops, education conferences and seminars, mentoring programmes and peer observation.

Researchers from the University of Bristol, in collaboration with the National Institute for Educational Sciences in Beijing, examined the effectiveness of PLCs to promote learning outcomes and teacher development in Chinese secondary schools.

Improving Teacher Development and Educational Quality in China (20102014) looked at the nature of teachers' professional development, specifically the role of PLCs. A key purpose of the study was to explore the views and experiences of senior staff, teachers and students as well as national and local policymakers regarding the existence and relevance of the PLC concept to improve teacher quality and learning gains. The project's findings indicate that the practice of sharing and critically interrogating working practices has the potential to enhance teacher effectiveness and bring about improved quality and equity in the Chinese education system.

Qualitative data was collected from four Chinese secondary schools in a mixture of urban and rural locations in two regions of mainland China, central eastern and western. One-to-one and focus group interviews were used as the main method of data collection, as well as follow-up reports, telephone interviews and feedback from workshops. These led to 'case study' schools being identified to receive an introduction to PLC concepts and methods. Participants were specifically asked their views in relation to the PLC operation in their own school.

\section{Key findings}

- The concept of PLCs exists

More than 80 per cent of teachers surveyed were engaging in PLC activities such as courses and workshops, education conferences and seminars, mentoring programmes, peer observation and informal dialogue. Teachers recognised the relevance and value of PLCs for their work.

SEE ALSO:

Thomas, S.M. (2014) Improving Teacher Development and Educational Quality in China: Examining Schools as Professional Learning Communities: ESRC End of Award Report, RES 167-25-0428. Swindon: ESRC

Thomas, S.M.; Peng, W-J. and Triggs, P. (2017) 'Professional Learning Communities in Chinese

\section{- The quality and definition of PLCs in schools vary}

The quality and type of PLC activities varied between schools and regions and were heavily dependent on available resources, local culture and values in efforts to promote collective responsibility for learning practices.

\section{- PLCs can improve professional development practices}

Teachers noted how PLCs helped to improve teaching and evaluation practices. Staff reported that engaging in such activities had enabled them to improve their reflective teaching practices.

\section{- Key features of PLCs were identified}

Commonalities identified included: shared values and vision; collective responsibility for students' learning; and collaboration focused on group as well as individual professional learning.

\section{- Reflective enquiry identified as a key component to professional development}

The process of individual professional reflective enquiry was perceived as important but many of those interviewed suggested that it was often confined to students' academic performance, mainly because this was a key indicator for evaluating teacher performance and student entry to higher education.

- Inclusion and trust were also seen as central to PLC development Inclusion of non-teaching staff, parents and community as well as trust and respect were also seen as central to PLC development. However, because PLC development often takes place in a highly competitive environment, with fixed hierarchies and a lack of shared leadership, it is a challenge to generate enough trust, respect and inclusion to enable the PLC to flourish.

\section{- Leadership is important for empowering teachers}

It was noted that the leadership of the head teacher and support from the whole district were important for empowering teachers to take more responsibility themselves for their own learning and for school improvement.

The key findings suggest educational reform in China can be enhanced through PLCs if tailored to the Chinese context. Aspects that may need to be considered in refining the concept in China include recognising differences between east/west and rural/urban contexts, and the strength of existing pedagogies, hierarchies and competition.

The research findings have been used to create a freely available toolkit for Chinese and other East Asian teachers to enhance PLCs in their own school. The toolkit summarises key evidence and identifies best practice in how PLCs are cultivated, evaluated and sustained in Chinese schools. It is designed for teachers, school leaders and teacher trainers. The project team have ongoing links with Ministry of Education policymakers in China and Vietnam to support PLC development and teacher training events.

Project title: Improving teacher development and educational quality in China: examining schools as professional learning communities.

\section{Professor Sally Thomas}

Professor of Education

School of Education, University of Bristol, UK 


\section{Transforming teaching quality through active learning in Ethiopia}

Despite a series of national education reform programmes designed to improve teaching quality, traditional teacher-centred 'lecturing' remains widely practised in Ethiopian schools. Researchers from Durham and Addis Ababa Universities together with partners in Ethiopia are looking to address some of the constraints of this method by devising strategies to improve the quality of science teaching.

The project Transforming the Pedagogy of Science, Technology, Engineering and Mathematics Subjects (TPSS) (2015-2018) trained primary school science teachers in ten Colleges of Teacher Education (CTE) across Ethiopia to use teacher-to-student and student-tostudent dialogue to support the learning of physics.

The project sought to help teachers to provide more meaningful engagement with their students by supporting them to ask questions, provoke student responses and use these effectively in their teaching. Student-to-student dialogue was also encouraged via pre-prepared activities which prompted them to openly discuss physics concepts.

Phase 1 observed teachers' practices before and after they were introduced to dialogical teaching. In this phase, 11 lecturers from six CTEs were given intervention training at the beginning of the 2015/16 academic year and implemented dialogical teaching into physics courses during that year. A control group from four CTEs was established for comparison. A total of 449 student teachers from both groups took part.

Phase 2 worked with teachers and students (Grades 7 and 8) from 52 different schools across Ethiopia. The 11 lecturers from the treatment group in Phase 1 helped to deliver intervention training to the physics teachers. This phase tested strategies for bringing about lasting change to teacher practices and student learning by introducing both pre-service teacher training and professional development for experienced teachers.

By monitoring changes using video and interview data, researchers found that when teachers adopted more learner-centric methods of teaching - including using a wider repertoire in their speech and providing more opportunities for students to engage in group discussions - students' levels of engagement and learning increased and they were more able to understand abstract scientific concepts. Teachers demonstrated improved skills in handling dialogue with their students, realising the need to reflect on students' answers before proceeding.

The biggest change came from teachers who had been exposed to both pre-service and professional development training. For example, in the Phase 1 control group teachers who did not receive the intervention spent on average 73 per cent of the time on lecturing. This was reduced to 22 per cent in the treatment group (from 80 per cent before the intervention) in favour of other teaching strategies such as group work, whole class discussion and presentations. Students in the group receiving the intervention performed significantly better than those who did not

\section{SEE ALSO:}

TPSS research project website: www.aau.edu.et/tpss/

Kind, P.; Kind, V.; Alemu, M.; Tadesse, M.; Atnafu, M.; Michael, K. and Rajab, T. (2018) 'From Didactic to Dialogical Teaching - Intervention to Foster Scientific Argumentation and Dialogical Teaching in Ethiopian Teacher Education', presented at the 26th Conference of the Southern African Association for Research in Mathematics,Science and Technology Education (SAARMSTE), University of Botswana, Gaborone, Botswana, 16-19 January 2018.

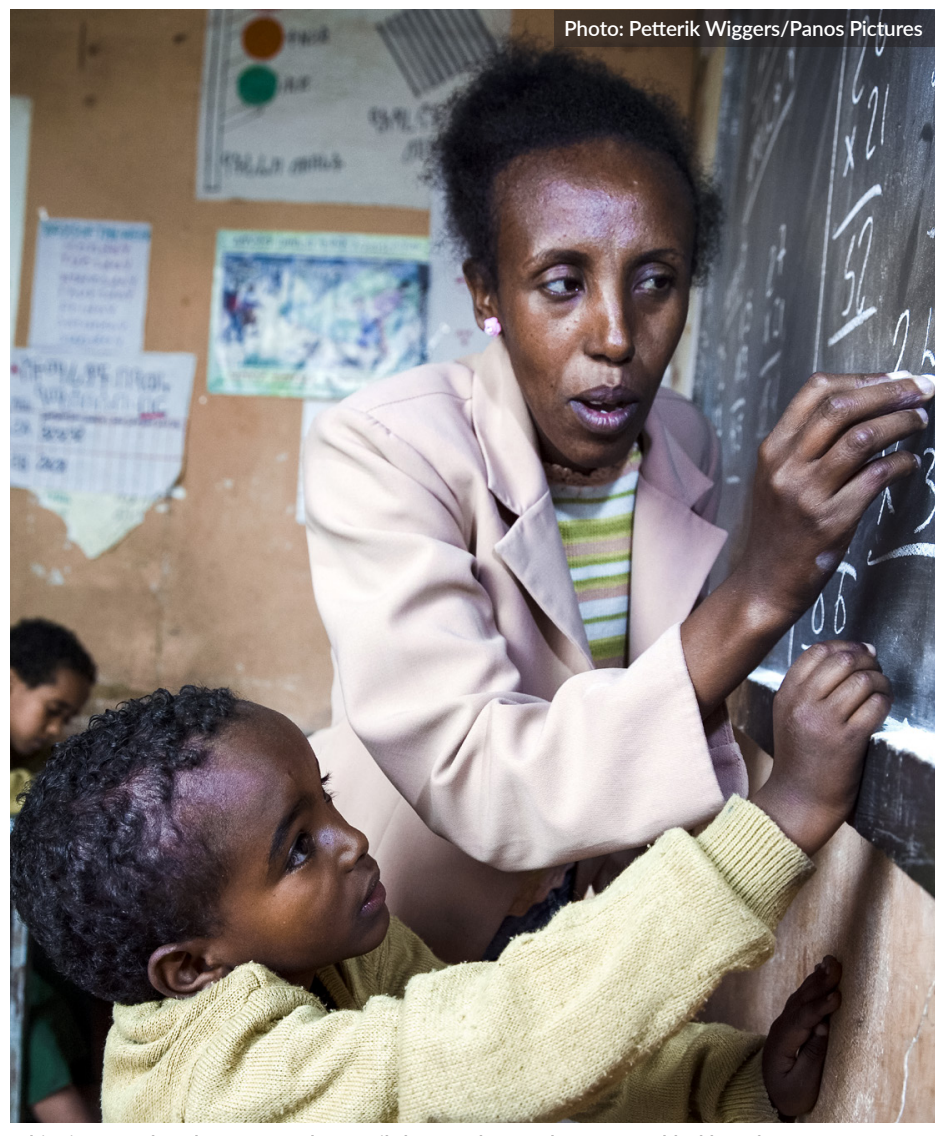

Ethiopia: A teacher shows one of her pupils how to do a maths sum on a blackboard.

when given a reasoning test after one academic year of experiencing dialogical teaching. Student responses improved in length and depth, with students supporting their responses with better reasoning.

The findings provide evidence to the Ethiopian Ministry of Education about how best to improve STEM teacher education and science learning. A national network of CTE lecturers, academic researchers and teachers is being established to ensure that the practice is applied to other subjects. A network is being set up through a series of meetings in Addis Ababa and attendees include a mix of national policymakers and 'TPSS ambassadors' who are staff who experienced the project and changed their teaching practices. It is hoped that the network will develop opportunities to transform the educational opportunities of many students.

Project title: Transforming the Pedagogy of STEM (Science, Technology, Engineering and Mathematics) Subjects (TPSS).

\section{Dr Vanessa Kind \\ Reader in Education \\ School of Education, University of Durham, UK}




\section{THE IMPACT INITIATIVE}

For International Development Research

This summary highlights the key messages from research focusing on quality teaching from the ESRC-DFID Joint Fund for Poverty Alleviation and Raising Learning Outcomes in Education Systems Research Programme, and is an output of the Impact Initiative for International Development Research.

It is written in collaboration with research teams and edited by Elizabeth Tofaris, the Impact Initiative Communications Specialist based at the REAL Centre, Faculty of Education, University of Cambridge.

The Impact Initiative seeks to connect policymakers and practitioners with the world-class social science research supported by the ESRC-DFID Strategic Partnership, maximising the uptake and impact of research from: (i) the Joint Fund for Poverty Alleviation Research; and (ii) the Raising Learning Outcomes in Education Systems Research Programme. We seek to identify synergies between these programmes and their grant holders, support them to exploit influencing and engagement opportunities, and facilitate mutual learning. The Impact Initiative is a collaboration between the Institute of Development Studies (IDS) and the University of Cambridge's Research for Equitable Access and Learning (REAL) Centre.

Email: info@theimpactinitiative.net

Website: www.theimpactinitiative.net

y@the_Impact Init \#impactlessons

All content is available under the Open Government License v3.0, except where otherwise stated

$\mathrm{E} \cdot \mathrm{S} \cdot \mathrm{R} \cdot \mathrm{C}$ ECONOMIC \& SOCIAL RESEARCH C OUNCI L

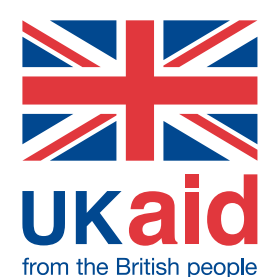

Research jointly supported by the ESRC and DFID 